Revista Mexicana de Análisis de la Conducta • Mexican Journal of Behavior Analysis 2019 | Núm. 1 • junio | No. 1 • June | Vol. 45, 111 - 131

http://dx.doi.org/10.5514/rmac.v45.i1.70871

\title{
EFECTOS DE DIFERENTES CORRECCIONES DE ERRORES SOBRE LA ADQUISICIÓN DE DISCRIMINACIONES CONDICIONALES
}

\section{EFFECTS OF DIFFERENT ERROR CORRECTIONS ON CONDITIONAL DISCRIMINATIONS ACQUISITION}

\author{
Raúl Ávila \\ Universidad Nacional Autónoma de México \\ Andrés García, María Teresa Gutiérrez \\ Universidad de Sevilla \\ Brasil Baltazar \\ Universidad Nacional Autónoma de México
}

Raúl Ávila y Brasil Baltazar están adscritos a la Facultad de Psicología, Universidad Nacional Autónoma de México; Andrés García y María Teresa Gutiérrez laboran en la Facultad de Psicología, Universidad de Sevilla. El primer autor, agradece al Programa de Apoyos para la Superación del Personal Académico de la UNAM (PASPA), de la Dirección General de Asuntos del Personal Académico, por la beca recibida para conducir el proyecto sobre discriminación condicional durante una Estancia Sabática en la Universidad de Sevilla de agosto de 2018 a enero de 2019. Los autores agradecen la ayuda a distancia para la conducción del estudio de los colaboradores del Laboratorio de Análisis Experimental de la Conducta en México; en particular a Luz Mancera, Violeta Olguín, César A. Corona, Meztli Miranda y Brenda E. Ortega. El primer autor puede ser contactado en el cubículo 205-C, Facultad de Psicología, UNAM. Av. Universidad 3004, Col. Copilco-Universidad, C.P. 04510, Ciudad de México, México. Correo electrónico: raulas@unam.mx 


\title{
Resumen
}

Se expuso a adultos a un procedimiento de discriminación condicional encadenada o uno con emparejamiento, con imágenes o nombres de pintores, sus nacionalidades y sus obras como estímulos muestra y de comparación. Después de las pruebas preliminares, se condujo el entrenamiento con las respuestas correctas seguidas por una consecuencia positiva y las incorrectas por una de cinco posibles correcciones por los errores. Estas podían ser: continuar con el siguiente ensayo (sin corrección), reiniciar el ensayo con la presentación señalada o no del estímulo muestra, reiniciar el ensayo en presencia del estímulo de comparación o una consecuencia de castigo positivo. Se asignó a seis participantes a cada una de las cinco condiciones de corrección durante 80 ensayos correctos o totales, dependiendo del tipo de corrección. Posteriormente, se condujeron las pruebas de las relaciones derivadas de reflexividad, simetría, transitividad y equivalencia. En general, hubo pocos aciertos en la condición de imágenes sin corrección. La ejecución fue mejor en el procedimiento de discriminación condicional con emparejamiento que en el procedimiento encadenado. Se concluyó que corregir los errores, así como los procedimientos de discriminación condicional con emparejamiento facilitan la adquisición de la discriminación condicional.

Palabras clave: discriminación condicional encadenada, discriminación condicional con emparejamiento, tipos de estímulos, corrección por errores, humanos

\begin{abstract}
Adults were exposed to a chained or a paired conditional discrimination procedure, with images or names of painters, their countries of origin, and their paintings as sample or comparison stimuli. After preliminary tests, training was conducted in which correct responses were followed by a positive outcome and incorrect ones by one out of five possible corrections. Corrections could be to continue to the next trial (no correction), to restart the trial with the signaled or not-signaled presentation of the sample stimulus, to restart the trial in the presence of the comparison stimuli, or a consequence of positive punishment. Six participants were assigned to each correction condition for 80 trials -correct or total trials, depending on the type of correction. Afterwards, derived-relation tests of reflexivity, symmetry, transitivity and equivalence were conducted. In general, participants had fewer correct
\end{abstract}


responses on the condition using images and no correction. Performance was better in the paired conditional discrimination procedure than in the chained procedure. It was concluded that correcting errors and using paired conditional discrimination tasks, facilitated the acquisition of conditional discriminations.

Keywords: chained conditional discrimination, paired conditional discrimination, stimuli types, error corrections, humans

La investigación sobre discriminaciones condicionales y la formación de clases de estímulos equivalentes se enfoca en averiguar las variables responsables de la adquisición de relaciones entre estímulos bajo situaciones de entrenamiento explícito y en la ocurrencia de relaciones derivadas entre estos. Un procedimiento común para estudiar la adquisición de las discriminaciones condicionales es el de igualación a la muestra. En este procedimiento se presenta a un participante un estímulo muestra que es seguido por dos o más estímulos de comparación; conforme a la relación que se desea entrenar, la elección del estímulo de comparación semejante (o diferente) al estímulo muestra resulta en la entrega de una recompensa preestablecida (Sidman, 2000). A partir de este procedimiento básico se han implementado variaciones de este, que se identifican con diferentes nombres y en los cuales se han probado varios tipos de estímulos muestra y de comparación, arreglos temporales y espaciales entre los mismos, tipos de consecuencias, etc. (ver García, 2018; Green \& Saunders, 1998; Saunders \& Williams, 1998 para revisiones amplias de los procedimientos).

Un producto del entrenamiento en discriminación condicional es la formación de equivalencia entre estímulos; por ejemplo, después de entrenar una relación A-B y una B-C, se pueden probar las relaciones derivadas de reflexividad, simetría, transitividad y equivalencia, entre los estímulos (Sidman, 1971; Sidman \& Tailby, 1982). Brevemente, las pruebas de las relaciones derivadas consisten en igualar los estímulos consigo mismos conforme al principio de reflexividad $(\mathrm{A}=\mathrm{A}, \mathrm{B}=\mathrm{B}$ y $C=C$ ), relacionarlos por simetría (si $A=B$ entonces $B=A$; si $B=C$ entonces $C=B$ ), mostrar transitividad ( $\mathrm{si} \mathrm{A}=\mathrm{B}$ y $\mathrm{B}=\mathrm{C}$ entonces $\mathrm{A}=\mathrm{C}$ ) y equivalencia (si $\mathrm{A}=\mathrm{B}$ y $\mathrm{B}=\mathrm{C}$ entonces $\mathrm{C}=\mathrm{A}$ ).

Algunos teóricos han probado procedimientos de entrenamiento o de corrección de errores que podrían facilitar la adquisición de las discriminaciones condicionales entre estímulos y probablemente también contribuyan a la ocurrencia de las relaciones derivadas entre los mismos. Por ejemplo, Caballero (2017) probó, con adultos de diferente nivel educativo, el entrenamiento simultáneo de la relación A-B y B-C sobre la adquisición de las discriminaciones condicionales y las relaciones 
derivadas entre los estímulos con un procedimiento de discriminación condicional con emparejamiento o uno de discriminación condicional encadenada; utilizando imágenes o palabras como estímulos muestra y de comparación. En el primer procedimiento, la autora expuso a los participantes al entrenamiento de relaciones entre estímulos A-B y B-C con un procedimiento de discriminación condicional con emparejamiento en el cual dado un estímulo muestra $\mathrm{A}$, las respuestas correctas al estímulo de comparación $\mathrm{B}$ fueron acompañadas por la recompensa y el estímulo $\mathrm{C}$ correspondiente. En contraste, en el procedimiento de discriminación condicional encadenada, dado el estímulo muestra $\mathrm{A}$, la respuesta correcta al estímulo de comparación $\mathrm{B}$ fue seguida por la presentación del estímulo $\mathrm{B}$ ahora como muestra y los estímulos de comparación C; la respuesta correcta al estímulo C de comparación correcto fue seguido por la recompensa. La autora encontró que todos los participantes adquirieron las relaciones entre estímulos independientemente del tipo de estímulo y del procedimiento de entrenamiento de discriminación empleados. Sin embargo, el porcentaje de aciertos en las pruebas de simetría, transitividad y equivalencia fue consistentemente más alto en el procedimiento de discriminación condicional encadenada que en el procedimiento de discriminación condicional con emparejamiento.

Por otro lado, Ruiz, Quesada, García, y Gutiérrez (2017) expusieron a niños, adolescentes y adultos jóvenes a un procedimiento de igualación a la muestra para probar los efectos de presentar diferentes tipos de correcciones por los errores sobre la adquisición de las discriminaciones condicionales. La corrección por los errores consistió en repetir el ensayo en el cual se eligió el estímulo de comparación incorrecto, tantas veces como fuera necesario hasta que se elegía el estímulo de comparación correcto. Emplearon las letras A, B, C y D como estímulos muestra y cuatro caracteres chinos como estímulos de comparación, cada uno asociado a una letra. Los tipos de corrección fueron castigo positivo en el cual la elección del estímulo de comparación incorrecto fue seguido por una leyenda que indicaba el error y un ruido de una explosión; la condición de seguimiento de reglas consistió en resaltar el estímulo de comparación correcto; la corrección al estímulo muestra consistió en reiniciar el ensayo con la presentación del mismo estímulo muestra; en la corrección al estímulo de comparación se reinició el ensayo con la presentación simultánea del estímulo muestra y los estímulos de comparación previamente presentados. Los autores encontraron que implementar una corrección por error resultó en un número de ensayos de entrenamiento correctos claramente mayor que en la ausencia de correcciones. Entre los cuatro tipos de corrección sólo hubo una 
diferencia significativa entre el castigo positivo y la corrección llevada al estímulo de comparación. Sin embargo, Ruiz et al. no condujeron pruebas de equivalencia entre los estímulos.

En resumen, Caballero (2017) encontró que los procedimientos de discriminación condicional encadenada y con emparejamiento fueron igualmente efectivos para adquirir discriminaciones condicionales; pero el primero resultó en una mejor ejecución en las pruebas de las relaciones derivadas que el segundo. Por otro lado, Ruiz et al. (2017) encontraron que presentar consecuencias por los errores en comparación con la ausencia de éstas, facilitó la adquisición de las discriminaciones condicionales entre estímulos. Tanto Caballero como Ruiz et al., destacaron la utilidad de sus procedimientos para acelerar la adquisición de las discriminaciones condicionales; sin embargo, sólo Caballero probó la ocurrencia de las relaciones derivadas entre los estímulos. Así, en este estudio se intentó aumentar la generalidad de los procedimientos y hallazgos de Caballero en combinación con los tipos de corrección por el error descritos por Ruiz et al. Por lo tanto, se averiguaron los efectos del tipo de entrenamiento combinado con las diferentes consecuencias por los errores sobre la adquisición de las discriminaciones condicionales y la ocurrencia de las relaciones derivadas entre estímulos. Aun cuando Caballero no encontró diferencias por el tipo de estímulo, con el único propósito de mantener la comparabilidad con su estudio, se reprodujeron sus procedimientos tanto con imágenes como palabras como estímulos muestra y de comparación.

\section{Método}

\section{Participantes}

Participaron 120 estudiantes de licenciatura de entre 18 y 22 años, 90 mujeres y 30 hombres. Se invitó a los participantes a través de redes sociales y cada uno recibió cuatro bolígrafos como gratificación por su colaboración.

\section{Aparatos}

El experimento se condujo en una habitación de $4 \times 2 \mathrm{~m}$ con cinco escritorios separados con muros de tablaroca. Cada escritorio estaba equipado con una silla y una computadora; se utilizaron tres computadoras con un monitor de 22 pulgadas, un ratón óptico y unos audífonos de diadema. El botón izquierdo del ratón de la 
computadora se utilizó como operando. Durante la sesión, se mantuvo prendido un generador de ruido blanco para minimizar los ruidos externos.

Las pruebas experimentales consistieron en presentaciones hechas en Microsoft Office PowerPoint 2013 y se emplearon como estímulos 12 imágenes y 12 palabras correspondientes a pintores, sus nacionalidades y obras representativas; se formaron cuatro clases de estímulos y cada una se componía de tres estímulos (A, B y C). El estímulo A se definió como "Pintor" y dependiendo de la modalidad del estímulo, éste fue una fotografía o el nombre escrito del pintor. El estímulo B correspondió a la "Nacionalidad del pintor" que como imagen fue la bandera del país y como palabra fue el nombre del país. El estímulo C fue "Obra del pintor" que como imagen fue la obra pictórica y como palabra fue el título de la misma. Los estímulos específicos (palabras o imágenes) se muestran en las Tablas 1 y 2 , respectivamente.

Se utilizó el programa Camtasia 8 Full para videograbar tanto la presentación de los estímulos como los clics que hicieron los participantes en la pantalla del monitor durante la sesión experimental. Para analizar estos videos, se programó un registro observacional en Visual Basic.NET 4.5.2 para contar los clics que los participantes emitieron sobre los estímulos presentados durante la sesión. Con el programa Camtasia se obtuvo un archivo txt con la lista de los eventos que ocurrieron durante la sesión.

\section{Procedimiento}

Antes de comenzar la sesión, el experimentador puso en la computadora la primera prueba y comenzó a grabar la pantalla con el programa Camtasia. En cuanto entró el participante, se le entregó un consentimiento informado y, una vez que empezó con las tareas, se prendió el ruido blanco. Se pidió al participante que se sentara frente a la computadora, se colocara los audífonos y leyera las instrucciones que estaban en la pantalla. Las cuales fueron:

"A continuación, aparecerá en la pantalla una imagen/palabra sobre la cual debe dar clic; una vez que lo haga, aparecerán cuatro imágenes/palabras más en cada esquina de la pantalla. Deberá elegir sólo una, la que usted crea que vaya o se relacione con la imagen/palabra que aparecerá al principio. Siempre que aparezca una imagen/palabra deberá seguir con el mismo procedimiento. Comprobará que el propio programa le irá indicando si su ejecución es correcta o no. Cuando esté listo dé clic en el botón INICIAR." 
Tabla 1. Estímulos en formato palabra

\begin{tabular}{lccc}
\hline & Estímulo A & Estímulo B & Estímulo C \\
\hline Clase $\mathbf{1}$ & Mauricio Rugendas & Alemania & El malón \\
\hline Clase $\mathbf{2}$ & Andrés Masson & Francia & Volviendo a la ejecución \\
\hline Clase 3 & Víctor Brauner & Rumania & Adán y Eva \\
\hline Clase 4 & Miguel Condé & México & Disputa de Oráculos \\
\hline
\end{tabular}

Tabla 2. Estímulos en formato imagen

Clase 1


Dependiendo del tipo de estímulo empleado, en las instrucciones previas solo apareció el término imagen o palabra. Se le pidió al participante que siempre que apareciera en el monitor la leyenda ;Gracias por tu participación! le avisara al experimentador, para que éste último iniciara la siguiente prueba. Una vez que el experimentador puso la prueba correspondiente en el monitor, dio la única instrucción “Una vez más, por favor”. Se procedió de esta manera con las tres fases que compusieron la prueba experimental; las cuales fueron: pre-entrenamiento, entrenamiento y post-entrenamiento, que se describirán posteriormente. Un aspecto de procedimiento común en las tres fases fue que siempre se presentó un estímulo muestra en el centro de la pantalla y una vez que el participante daba clic sobre éste (una respuesta de observación), aparecían cuatro estímulos de comparación, uno en cada esquina de la pantalla. En cada ensayo, el estímulo muestra estaba relacionado sólo con un estímulo de comparación y elegir el correcto se contó como una respuesta correcta.

A continuación, se describen las tres fases de la sesión experimental.

\section{Fase 1: Pre-entrenamiento}

Estas pruebas fueron las mismas para todos los participantes, únicamente varió la modalidad del estímulo. Se averiguó si los participantes conocían las relaciones entre estímulos que se entrenarían. En una primera prueba, se evaluó la relación entre los estímulos A y el B y en una siguiente prueba se evaluó la relación entre los estímulos $\mathrm{B}$ y el C. Cada relación entre estímulos se presentó dos veces y, por lo tanto, se expuso al participante a un total de ocho ensayos en la prueba A-B, y otros ocho ensayos en la prueba B-C.

Cada ensayo inició con la presentación del estímulo muestra en el centro de la pantalla. Una vez que el participante emitía una respuesta de observación se presentaba el mismo estímulo muestra con sus cuatro estímulos de comparación. Después de que el participante había escogido un estímulo de comparación, fuera o no el correcto, se pasaba al siguiente ensayo. Independientemente del número de aciertos se pasó a la siguiente fase.

\section{Fase 2: Entrenamiento}

Se emplearon los procedimientos de discriminación condicional encadenado y con emparejamiento, con imágenes o palabras como estímulos muestra y de comparación. En cada procedimiento se implementaron cinco condiciones de corrección por los errores. Así, el diseño fue un factorial $2 \times 2 \times 5$ (dos procedimientos de entrenamiento por dos tipos de estímulos y cinco condiciones de corrección por 
los errores). Se asignaron seis participantes a cada combinación de las variables y el número de ensayos correctos por sesión fue la variable dependiente registrada. Las condiciones de corrección por los errores fueron: sin corrección, corrección señalada a la muestra, corrección no señalada a la muestra, corrección no señalada a la comparación o castigo positivo señalado. Al final de la descripción de la fase de entrenamiento se describirán con detalle estas condiciones porque son comunes a los dos procedimientos de entrenamiento empleados.

\section{Procedimiento de discriminación condicional con emparejamiento}

El entrenamiento inició con un clic en el botón con la leyenda INICIAR. En cada ensayo se presentó el estímulo muestra A y el participante tenía que hacer clic sobre el mismo para que aparecieran el mismo estímulo A y los cuatro estímulos de comparación B. Si el participante daba clic en el estímulo de comparación B que correspondía al estímulo muestra A; esto es, una relación A-B correcta, se presentaba una recompensa positiva. La recompensa consistió en un emoticono feliz y un sonido de aplausos durante cinco segundos acompañado por el estímulo C. Posteriormente, inició un intervalo entre ensayos de dos segundos durante el cual el monitor permaneció en negro. El siguiente ensayo inició con la presentación de un nuevo estímulo muestra $\mathrm{A}$.

En caso de no responder a la relación A-B correcta; es decir, si el participante daba clic sobre cualquiera de los otros tres estímulos de comparación B, se presentaba una corrección por el error.

\section{Procedimiento de discriminación condicional encadenada}

Una vez que se inició el entrenamiento en este procedimiento, se presentó en la pantalla el estímulo muestra A sobre el cual el participante tenía que hacer clic para que aparecieran los cuatro estímulos de comparación B (primer eslabón). Si el participante relacionaba correctamente los estímulos A-B, entonces se presentaba el estímulo $\mathrm{B}$ en el centro del monitor como estímulo muestra acompañado por cuatro estímulos de comparación C (segundo eslabón). Si el participante emitía la respuesta correcta a la relación $B-C$, se presentaba una consecuencia positiva que consistió en la leyenda Bien hecho, acompañada de un sonido de aplausos durante 5 segundos. Inmediatamente después, se inició un intervalo entre ensayos de 2 segundos en el que la pantalla permaneció de color negro. El siguiente ensayo inició con la presentación de otro estímulo muestra A. En caso contrario, si el participante respondía a una relación entre estímulos incorrecta en el primer o en el segundo eslabón del programa (A-B/ B-C, respectivamente), se presentaban las consecuencias correspondientes al tipo de corrección programado. 


\section{Duración del Entrenamiento y Tipos de corrección}

En los dos procedimientos de discriminación condicional, el entrenamiento terminó cuando el participante completó 80 ensayos correctos o menos, lo cual dependió de la corrección programada. En algunas condiciones dada la contingencia programada sólo se condujeron 80 ensayos, correctos o no. En otras condiciones cada error en el mismo ensayo lo reiniciaba y por esta razón se condujeron los ensayos necesarios hasta que se completaron 80 ensayos correctos. Los tipos de corrección empleados fueron los siguientes:

Sin corrección

Si se elegía el estímulo de comparación incorrecto de la relación A-B o B-C, iniciaba un intervalo entre ensayos de $2 \mathrm{~s}$ (pantalla negra) y posteriormente iniciaba el siguiente ensayo.

\section{Corrección señalada al estímulo muestra}

Si se elegía un estímulo de comparación incorrecto para la relación A-B o B-C se presentaba la leyenda Inténtalo de nuevo y ésta última se mantenía presente hasta que el participante pasaba el cursor sobre ella. Posteriormente, se reiniciaba el ensayo con la presentación del primer estímulo muestra A y el participante tenía que volver a emitir una respuesta de observación.

Corrección no-señalada al estímulo muestra

Si se elegía un estímulo de comparación incorrecto para la relación A-B o B-C, iniciaba un tiempo fuera de 2 s y se presentaba de nuevo el estímulo muestra A del mismo ensayo. El participante tenía que volver a emitir una respuesta de observación.

\section{Corrección no-señalada al estímulo de comparación}

La elección del estímulo de comparación incorrecto de la relación A-B o B-C resultó en la presentación del estímulo muestra $\mathrm{A}$ acompañado de los cuatro estímulos de comparación B del mismo ensayo.

\section{Castigo positivo señalado}

Si se escogía el estímulo de comparación incorrecto de la relación A-B o B-C se presentaba un castigo positivo que consistió en presentar la pantalla en blanco con la leyenda ${ }_{j} T e$ equivocaste! y un sonido de explosión durante $5 \mathrm{~s}$. Después de un intervalo entre ensayos de $2 \mathrm{~s}$ se presentaba el estímulo muestra A del siguiente ensayo.

Nótese que, para los dos procedimientos de discriminación condicional, en las condiciones de corrección señalada y no señalada al estímulo muestra o al estímulo de comparación, el participante no podía pasar al siguiente ensayo hasta que emitiera la respuesta correcta. 


\section{Fase 3: Post-entrenamiento}

Se evaluó la adquisición de las relaciones derivadas entre los estímulos exponiendo a los participantes a siete pruebas de equivalencia. Tres de éstas, correspondieron a pruebas de reflexividad, una por cada estímulo ( $\mathrm{A}, \mathrm{B}$ y $\mathrm{C}$ ). Por ejemplo, en la prueba de reflexividad del estímulo A uno de los pintores fue el estímulo muestra y los cuatro pintores fueron los estímulos de comparación. Por tanto, cada prueba estuvo conformada por cuatro ensayos y cada ensayo inició con un estímulo muestra en el centro. Un clic en éste resultó en la presentación del mismo estímulo muestra y los cuatro estímulos de comparación correspondientes. Así, el participante tenía que seleccionar el estímulo de comparación que era igual al estímulo muestra. Independientemente de si la selección fue correcta o no, se pasó al siguiente ensayo.

Se evaluó simetría con dos pruebas, una evaluó la relación B-A y la otra C-B. Cada prueba consistió en cuatro ensayos. Se presentó un estímulo muestra (B o C) y un clic en éste resultó en la presentación del mismo estímulo muestra y cuatro estímulos de comparación (los estímulos A si el estímulo muestra fue B y los estímulos B si el estímulo muestra fue C). La tarea del participante consistió en elegir el estímulo de comparación que estuviera relacionado con el estímulo muestra correspondiente. Una vez que el participante seleccionó un estímulo de comparación, pasó al siguiente ensayo.

Para la prueba de transitividad, conformada por cuatro ensayos, se presentó un estímulo muestra A y un clic en éste resultó en la presentación del mismo estímulo muestra y cuatro estímulos de comparación C. El participante tenía que elegir el estímulo de comparación correspondiente al estímulo muestra. Una vez que seleccionó el estímulo de comparación, pasó al siguiente ensayo. Por último, para la prueba de equivalencia, también conformada por cuatro ensayos, se presentó un estímulo muestra $\mathrm{C}$ y un clic en éste resultó en la presentación del mismo estímulo muestra y cuatro estímulos de comparación A. El participante debía elegir el estímulo de comparación que estuviera relacionado con el estímulo muestra y, una vez que lo seleccionó, pasó al siguiente ensayo.

En todas las pruebas el último ensayo fue seguido por la leyenda ¡Gracias por tu participación!

\section{Resultados}

En las Figuras 1 y 2 se presenta, para el procedimiento de discriminación condicional encadenada con imágenes (Figura 1) y palabras (Figura 2) como estímulos muestra y de comparación, el porcentaje de ensayos correctos en cada fase del estudio 


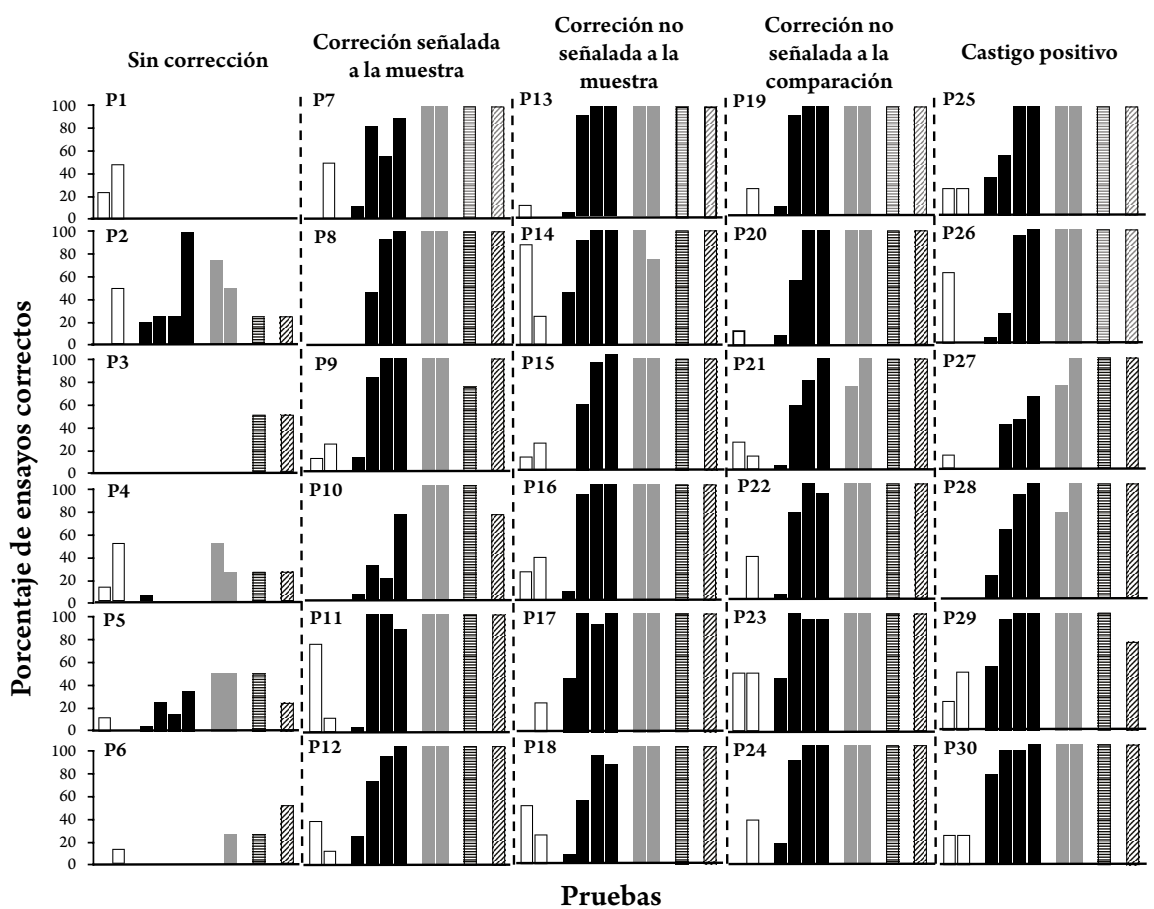

Figura 1. Porcentaje de ensayos correctos en el procedimiento de discriminación condicional encadenada con imágenes como estímulos para cada participante (paneles) por cada tipo de corrección por el error (columnas) en las tres fases de la sesión: preentrenamiento (barras blancas), entrenamiento dividido en cuartiles (barras negras) y post-entrenamiento (simetría, barras grises; transitividad, barras con rayas horizontales; equivalencia, barras con rayas diagonales).

(barras), para cada uno de los participantes (paneles) expuestos a cada condición de corrección por el error (columnas). Para cada participante, las barras blancas muestran los datos de las dos condiciones de pre-entrenamiento, las barras negras muestran los cuartiles del entrenamiento, las barras grises se refieren a las dos pruebas de simetría, BA y CB, las barras con rayas horizontales y diagonales muestran los datos de las pruebas de transitividad (AC) y equivalencia (CA), respectivamente. Dado que en las pruebas de reflexividad AA, BB y CC todos los participantes obtuvieron el $100 \%$ de ensayos correctos, se omitieron las barras correspondientes en la figura para ganar en claridad en la presentación de los otros datos. El número en la esquina superior izquierda de cada panel es el número de identificación de cada participante. 


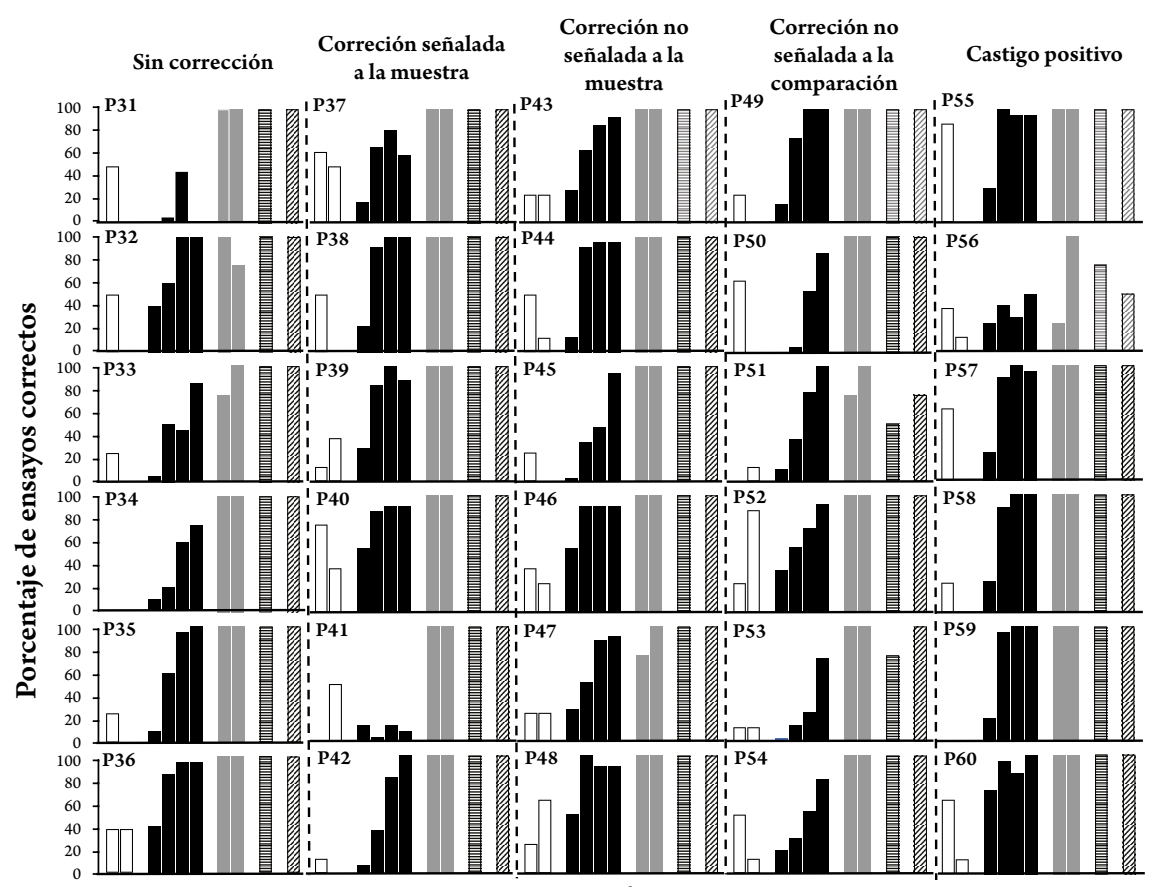

Pruebas

Figura 2. Porcentaje de ensayos correctos en el procedimiento de discriminación condicional encadenada con palabras como estímulos para cada participante (paneles) por cada tipo de corrección por el error (columnas) en las tres fases de la sesión: preentrenamiento (barras blancas), entrenamiento dividido en cuartiles (barras negras) y post-entrenamiento (simetría, barras grises; transitividad, barras con rayas horizontales; equivalencia, barras con rayas diagonales).

Como se muestra en la Figura 1 para el procedimiento de discriminación condicional encadenada con imágenes como estímulos, en el pre-entrenamiento A-B y $\mathrm{B}-\mathrm{C}$ el porcentaje de ensayos correctos se mantuvo entre 0 y $50 \%$ en la mayoría de los participantes; sólo para los participantes P11, P14 y P26 la variable dependiente osciló entre 70 y $90 \%$ en el pre-entrenamiento A-B.

Para analizar la adquisición de las discriminaciones condicionales y para comparar entre los participantes su ejecución en el entrenamiento, para cada uno se dividió el total de ensayos de su sesión en cuartiles y se calculó el porcentaje de ensayos correctos en cada uno de los cuartiles (barras negras en cada panel). Así, en la condición sin corrección por el error los participantes mostraron un número de 


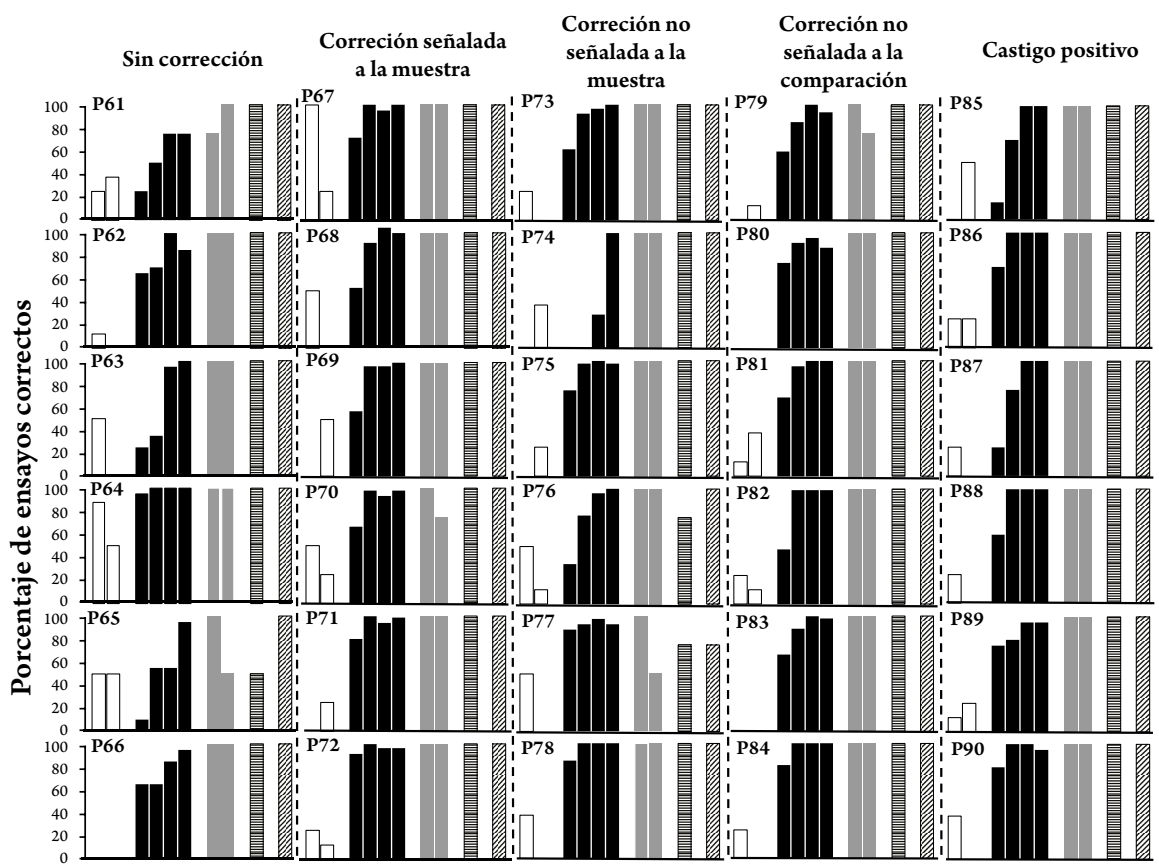

Pruebas

Figura 3. Porcentaje de ensayos correctos en el procedimiento de discriminación condicional con emparejamiento con imágenes como estímulos para cada participante (paneles) por cada tipo de corrección por el error (columnas) en las tres fases de la sesión: preentrenamiento (barras blancas), entrenamiento dividido en cuartiles (barras negras) y post-entrenamiento (simetría, barras grises; transitividad, barras con rayas horizontales; equivalencia, barras con rayas diagonales).

ensayos correctos muy bajo del principio al final de los ensayos de entrenamiento; la excepción fue el participante P2 que alcanzó un 100\% de ensayos correctos en el último cuartil. En las otras cuatro condiciones de corrección por los errores, se observó una tendencia creciente del primer al último cuartil del número de ensayos correctos; esto es, desde un número relativamente bajo de ensayos correctos en el primer cuartil hasta $100 \%$ de ensayos correctos en el tercer o último cuartil; sólo tres participantes no alcanzaron el máximo posible de ensayos correctos. Sin embargo, estas excepciones ocurrieron con dos participantes (P7 y P10) en el procedimiento de corrección señalada a la muestra y con uno (P27) expuesto a castigo positivo. Por lo tanto, los datos de estos participantes no parecen estar relacionados 


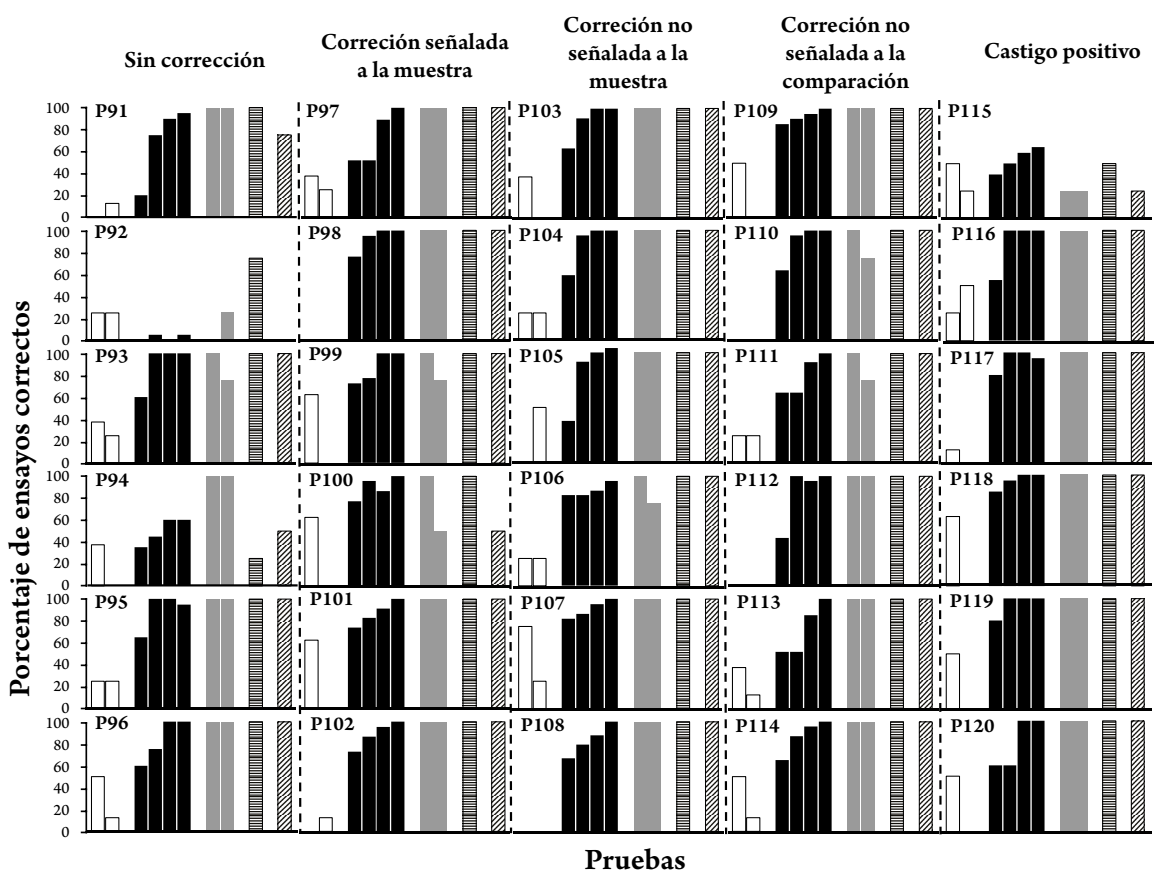

Figura 4. Porcentaje de ensayos correctos en el procedimiento de discriminación condicional con emparejamiento con palabras como estímulos para cada participante (paneles) por cada tipo de corrección por el error (columnas) en las tres fases de la sesión: preentrenamiento (barras blancas), entrenamiento dividido en cuartiles (barras negras) y post-entrenamiento (simetría, barras grises; transitividad, barras con rayas horizontales; equivalencia, barras con rayas diagonales).

con el procedimiento de corrección que les correspondió. Con respecto a las relaciones derivadas, sólo en la condición sin corrección por los errores se encontró que, en las dos pruebas de simetría, la prueba de transitividad y la de equivalencia el número de ensayos correctos varió entre 0 y $40 \%$ en los seis participantes expuestos a esta condición. En la condición de corrección señalada a la muestra un participante en la prueba de transitividad y el otro en equivalencia (P9 y P10) alcanzaron entre 80 y $90 \%$ de ensayos correctos. En la corrección no señalada a la muestra un participante (P14) en la prueba de simetría CB mostró un nivel de ensayos correctos de $80 \%$. En la corrección no señalada a la comparación sólo el participante P21 en simetría BA mostró un 75\% de ensayos correctos. En la condición de castigo posi- 
tivo P27 y P28 en simetría BA y P29 en equivalencia alcanzaron entre 80 y $90 \%$ de ensayos correctos.

Para el procedimiento de discriminación condicional encadenada con palabras como estímulos, como se muestra en la Figura 2, para todos los participantes en el pre-entrenamiento el número de ensayos correctos varió entre 0 y $60 \%$. Con respecto al entrenamiento la variable dependiente aumentó abruptamente de 0 a $100 \%$, o de una manera monotónica del primer al último cuartil en la mayoría de los participantes y condiciones de corrección por los errores. Excepto por algunos casos aislados, todos los participantes obtuvieron $100 \%$ de ensayos correctos en las pruebas de simetría, transitividad y equivalencia. Los demás participantes obtuvieron entre 30 y $80 \%$ de ensayos correctos en las diferentes pruebas de relaciones derivadas; estos casos fueron los siguientes: P32 en simetría CB, P33, P47, P51 y P56 en simetría BA, P51 y P53 en transitividad y P56 en transitividad y equivalencia.

En el mismo formato que las figuras anteriores, en las Figuras 3 y 4 se presenta, para el procedimiento de discriminación condicional con emparejamiento con imágenes (Figura 3) y palabras (Figura 4) como estímulos muestra y de comparación, el porcentaje de ensayos correctos de cada uno de los participantes (paneles) expuestos al pre-entrenamiento (barras vacías), entrenamiento (barras negras) y las pruebas de las relaciones derivadas (barras, grises, con rayas horizontales y con rayas diagonales para simetría, transitividad y equivalencia, respectivamente) y para las cinco condiciones de corrección por el error (columnas).

Para el procedimiento de discriminación condicional con emparejamiento con imágenes como estímulos y para todos los participantes, en el pre-entrenamiento se observó un porcentaje de ensayos correctos que varió entre 20 y $80 \%$ en el caso de las relaciones A-B y un porcentaje que varió entre 0 y $40 \%$ para las relaciones B-C.

En el entrenamiento, para todas las condiciones de corrección por los errores, el porcentaje de ensayos correctos fue de al menos $50 \%$ en el primer cuartil y aumentó rápidamente hasta el $100 \%$ de ensayos correctos entre el segundo y el tercer cuartil. Las excepciones fueron los participantes P61, P63, P65, P74, P76, P85 y P87 quienes mostraron un porcentaje de ensayos correctos menor al $50 \%$ en el primer cuartil; sin embargo, como todos los otros participantes, rápidamente alcanzaron el $100 \%$ de ensayos correctos en el segundo, tercer o último cuartil.

En algunos participantes, se observó un porcentaje de ensayos correctos menor al $100 \%$ en diferentes pruebas de las relaciones derivadas; estos participantes fueron: P61 en simetría AB; P65, P70, P77 y P79 en simetría CB; P65, P76 y P77 
en transitividad. Para todos los otros participantes se observó un 100\% de ensayos correctos en las tres relaciones derivadas.

Como ya se mencionó antes, en la Figura 4 se muestran los datos obtenidos con el procedimiento de discriminación condicional con emparejamiento y palabras como estímulos. En las dos pruebas de pre-entrenamiento se encontró que el porcentaje de ensayos correctos varió entre 0 y $60 \%$ en la mayoría de los participantes; sólo el participante P107 mostró un porcentaje de $80 \%$.

Con respecto al entrenamiento sólo el participante P92 tuvo un porcentaje de ensayos correctos virtualmente de cero en todos los cuartiles; para los participantes P94 y P115 la variable dependiente aumentó muy poco de un 40 a un $60 \%$ aproximadamente. Todos los demás participantes mostraron un porcentaje alrededor del $50 \%$ que, en la mayoría de los casos, aumentó abruptamente a 100\% en el segundo o tercer cuartil.

En las relaciones derivadas se encontró que para P92 y P115 la prueba de simetría BA mostró porcentajes de ensayos correctos cercanos a cero; para los participantes P92, P93, P99, P100, P106, P110, P111y P115 la prueba de simetría CB resultó en porcentajes de ensayos correctos que variaron entre 0 y $90 \%$. Con respecto a la prueba de transitividad, sólo los participantes P94 y P115 mostraron porcentajes menores a 100\%. Para los participantes P91, P92 P94, P100 y P115, la prueba de equivalencia resultó en porcentajes de ensayos correctos que variaron entre 0 y $80 \%$.

\section{Discusión}

Se averiguaron los efectos de combinar el procedimiento de discriminación condicional encadenada y el de discriminación condicional con emparejamiento con diferentes tipos de corrección por los errores sobre la adquisición de discriminaciones condicionales y la ocurrencia de las relaciones derivadas no entrenadas.

Conforme al propósito previo, en una primera fase, se expuso a todos los participantes a dos pruebas de pre-entrenamiento para averiguar si conocían las relaciones entre los estímulos que se emplearon. Se encontraron porcentajes de respuestas correctas relativamente bajos en la mayoría de los participantes. Por lo tanto, estos porcentajes de respuestas correctas se pueden considerar sólo como aciertos por azar y muestran que los participantes desconocían las relaciones entre estímulos que se entrenaron posteriormente. 
En la fase de entrenamiento, los principales hallazgos fueron los siguientes: primero, con respecto al tipo de estímulo empleado como muestra y de comparación sólo se encontró un número de ensayos correctos notablemente más bajo en los participantes expuestos a la condición sin corrección por el error con imágenes que el nivel de la variable dependiente en la misma condición con palabras como estímulos del procedimiento de discriminación condicional encadenada. Segundo, con respecto a los procedimientos de corrección sólo se encontró una diferencia notable en el número de ensayos correctos para la condición sin corrección por el error y las cuatro condiciones de corrección con imágenes como estímulos, en el procedimiento de discriminación condicional encadenada. Tercero, excepto por los participantes con imágenes y sin corrección por el error, no hubo diferencias en el número de ensayos correctos entre todas las condiciones de corrección por los errores tanto con imágenes como con palabras como estímulos de muestra y de comparación en ambos procedimientos.

Cuarto, con respecto al tipo de entrenamiento en discriminación condicional, se observó que para todos los participantes expuestos al procedimiento con emparejamiento el porcentaje de ensayos correctos en el primer cuartil fue notablemente más alto que el observado en el mismo cuartil en los participantes expuestos al procedimiento de discriminación condicional encadenada. Aún más, parece que el porcentaje de ensayos correctos aumentó más rápido del primer al último cuartil en los participantes expuestos al procedimiento con emparejamiento que en los expuestos al procedimiento encadenado. En breve, independientemente del tipo de corrección por los errores, el procedimiento de discriminación condicional con emparejamiento favoreció una adquisición más rápida de las relaciones entre estímulos entrenadas que el procedimiento de discriminación condicional encadenada; sin embargo, la ejecución final fue similar en ambos procedimientos. Este último hallazgo, además de ser congruente con el reportado por Caballero (2017), también extiende sus resultados de procedimientos con corrección señalada al estímulo muestra a procedimientos con otros tipos de corrección por los errores.

Para los dos procedimientos de entrenamiento en discriminación, las condiciones de corrección por el error resultaron en una ejecución similar en la tarea en contraste con la ausencia de corrección. Estos resultados son similares a los reportados por Ruiz et al. (2017) y muestran la generalidad de los efectos de diferentes tipos de corrección por los errores de un procedimiento de discriminación condicional simple a procedimientos en los cuales se entrenan en el mismo procedimiento dos relaciones entre estímulos; esto es, discriminación condicional encadenada y con 
emparejamiento. Los hallazgos previamente descritos, tanto para los tipos de procedimientos como de condiciones de corrección por los errores, fueron similares tanto con imágenes como con palabras como estímulos muestra y de comparación. Así, este último resultado extiende los hallazgos de Ruiz et al. a diferentes tipos de estímulos.

Como se mencionó en la introducción, Caballero (2017) expuso a adultos de diferente nivel educativo a sus dos procedimientos de entrenamiento en discriminación y encontró con el procedimiento de discriminación condicional encadenada una adquisición relativamente más rápida de la discriminación en los participantes con educación universitaria que en los que tenían menos preparación. En contraste, en el procedimiento de discriminación condicional con emparejamiento se encontró una ejecución similar entre los participantes, independientemente de su nivel de educación. Ruiz et al. (2017) por su parte probaron los diferentes tipos de corrección por los errores en participantes de diferente edad y encontraron que el efecto del tipo de corrección fue mayor en los sujetos de menor edad. En este contexto, en futuras investigaciones la combinación entre procedimientos de entrenamiento en discriminación y tipos de corrección por los errores que se probaron en el presente estudio, se pueden extender a sujetos de diferente edad y/o nivel socioeconómico. La viabilidad de esta sugerencia está apoyada por la literatura que ha mostrado la contribución de estas variables del participante sobre la adquisición de discriminaciones condicionales en humanos (cf. García, 2018, para una revisión sobre este tipo de variables).

Con respecto a las relaciones derivadas, en el caso de la reflexividad todos los participantes mostraron un $100 \%$ de ensayos correctos en su ejecución. En el caso de las pruebas de simetría, transitividad y equivalencia, en los casos en los cuales el porcentaje de ensayos correctos fue menor de $100 \%$, éste se relacionó con un porcentaje también menor al $100 \%$ en el último cuartil del entrenamiento; por ejemplo, en el caso de la condición con palabras y sin corrección por los errores.

Ruiz et al. (2017) comentaron ampliamente en su artículo las posibles razones de la falta de diferencias entre los procedimientos de corrección por los errores en cuanto a las relaciones entrenadas entre los estímulos y la ventaja de emplear estas correcciones en contraste con su ausencia. Por ejemplo, los autores comentaron que este hallazgo podría ser el resultado de la repetición de un mismo ensayo hasta que el sujeto emitía la respuesta correcta, lo cual fue una característica de las condiciones de corrección. Una explicación que fue congruente con los estudios de práctica positiva que comparten detalles de procedimiento similares como la repetición de la 
tarea hasta hacerla correctamente (cf. Ollendrick, Matson, Esveldt-Dawson \& Shapiro, 1980). Los resultados del presente estudio añadieron evidencia con respecto a la igualdad de las condiciones de corrección en cuanto a las relaciones derivadas observadas después del entrenamiento con todas las condiciones de corrección por los errores y en dos procedimientos de entrenamiento en discriminación condicional, encadenada y con emparejamiento.

Un resultado específico fue que, en el procedimiento de discriminación condicional encadenada, en la condición de ausencia de corrección por los errores se encontró que, con imágenes como estímulos tanto en el entrenamiento como en las relaciones derivadas probadas, la ejecución de los participantes fue notablemente baja en comparación con la misma condición de control con palabras como estímulos muestra y de comparación. Esta diferencia en resultados no se observó en el procedimiento de discriminación condicional con emparejamiento. No es clara la razón de esta diferencia, que puede atentar contra la generalidad entre estímulos en los procedimientos de entrenamiento en discriminación condicional. Una explicación es que posiblemente para los participantes las palabras tuvieron más "significado" que las imágenes en condiciones de entrenamiento en dos discriminaciones condicionales; un aspecto que caracterizó al procedimiento de este estudio. En breve, recientemente se ha demostrado que la adquisición de las discriminaciones condicionales puede estar modulada por el "nivel" de "significado" que tienen los estímulos muestra y de comparación para los participantes (e.g., Arntzen, Nartey, \& Fields, 2018).

\section{Referencias}

Arntzen, E., Nartey, R., \& Fields, L. (2018). Reorganization of equivalence classes: Effects of preliminary training and meaningful stimuli. JJournal of the Experimental Analysis of Behavior, 109(3), 564-586.

Caballero, C. (2017). Derivación de la relación entre estímulos mediante el entrenamiento en una sola fase (tesis de pregrado). Universidad de Sevilla, Sevilla, España. García, G. A. (2018). Aprendizaje Complejo. España: Librería San Bernardo. Green, G. \& Saunders, R. R. (1998). Stimulus Equivalence. En K.A., Lattal, \& M., Perone (Eds.), Handbook of Research Methods in Human Operant Behavior, pp. 229-262. New York: Plenum Press. 
Ollendrick, T. H., Matson, J. L., Esveldt-Dawson, K., \& Shapiro, E. S. (1980). Increasing spelling achievement: an analysis of treatment procedures utilizing an alternating treatments design. Journal of Applied Behavior Analysis, 13(4), 645-654.

Ruiz, M., Quesada, J., García, A., y Gutiérrez, M. T. (2017). Comparación de métodos de corrección de errores en la adquisición de discriminaciones condicionales. Revista Mexicana de Análisis de la Conducta, 43(1), 60-82.

Saunders, K. J., \& Williams, D. C. (1998). Stimulus-Control Procedures. En K. A. Lattal \& M. Perone (Eds.), Handbook of Research Methods in Human Operant Behavior, pp. 193-228. New York: Plenum Press.

Sidman, M. (1971). Reading and auditory-visual equivalences. Journal of Speech and Hearing Research, 14(1), 5-13.

Sidman, M., \& Tailby, W. (1982). Conditional discrimination vs. matching to sample: an expansion of the testing paradigm. Journal of the Experimental Analysis of Behavior, 37(1), 5-22.

Sidman, M. (2000). Equivalence relations and the reinforcement contingency. Journal of the Experimental Analysis of Behavior, 74(1), 127-146.

Recibido Enero 22, 2019 /

Received January 22, 2019

Aceptado Agosto 19, 2019 /

Accepted August 19, 2019 